\title{
EFEITO DA TEMPERATURA E EXTRATOS DE PLANTAS NO CONTROLE DA ANTRACNOSE DO FRUTO DA BANANEIRA (Musa sp.) CAUSADA POR Colletotrichum musae
}

Samara da Silva Oliveira $^{1}$; Sabrina Silva de Oliveira ${ }^{2}$, Josimar Batista Ferreira ${ }^{3}$; Gleisson de Oliveira Nascimento ${ }^{3}$; William Ferreira Alves ${ }^{3}$

1. Mestranda em Agricultura no Trópico Úmido pelo Instituto Nacional de Pesquisas da Amazônia - INPA, Manaus/AM - Brasil, samara oliveira12@hotmail.com

2. Doutoranda da Rede de Biodiversidade e Biotecnologia da Amazônia Legal pela

Fundação Oswaldo Cruz, Porto velho/RO - Brasil

3. Professor Doutor da Universidade Federal do Acre, Campus Floresta - Cruzeiro do Sul/AC - Brasil

Recebido em: 22/09/2018 - Aprovado em: 23/11/2018 - Publicado em: 03/12/2018 DOI: 10.18677/EnciBio_2018B39

\section{RESUMO}

Colletotrichum musae causa grandes prejuízos na cultura da banana, e por este motivo é considerado um importante agente fitopatogênico. Nesse sentido, o objetivo com este trabalho foi avaliar os efeitos da temperatura e de extratos vegetais de Citrus aurantifolia Swingle, Citrus latifolia Tanaka e Allium sativum sobre o crescimento micelial de $C$. musae. No efeito da temperatura foram avaliadas as temperaturas de $15,20,25,30,35$ e $40^{\circ} \mathrm{C}$ frente ao crescimento micelial de $C$. musae. O delineamento experimental utilizado foi 0 inteiramente casualizado, utilizando cinco repetições. Os dados foram submetidos à análise de variância (ANOVA) e as médias comparadas pelo teste Tukey (0.05). Na avaliação da atividade antifúngica foram adicionadas as concentrações de 0, 50, 100, 150 e 200

$\mathrm{L} / \mathrm{mL}$ dos extratos vegetais individualmente ao meio de cultura BDA. Os resultados das diferentes concentrações foram submetidos à análise de variância, associada ao teste de regressão linear simples e múltipla, ao nível de $1 \%$ de significância. Todas as análises foram realizadas utilizando a linguagem de programação $R$. As temperaturas de 25 e $30^{\circ} \mathrm{C}$ proporcionaram maior crescimento micelial do patógeno, com valores de IVCM de 1,7 e 1,3 cm.dia ${ }^{-1}$, respectivamente. No ensaio com os extratos de limão taiti e alho, todas as concentrações testadas apresentaram inibição do patógeno. O extrato de limão-galego apresentou os mesmos resultados do fungicida, inibindo o crescimento total do fungo. Os extratos vegetais em estudo apresentam potencial para o manejo alternativo da antracnose.

PALAVRAS-CHAVE: Controle fúngico, Doença pós-colheita, Fitopatógeno.

\section{EFFECT OF TEMPERATURE AND PLANT EXTRACTS ON THE CONTROL OF ANTHRACNOSE OF BANANA FRUIT (Musa sp.) CAUSED BY Colletotrichum musae}

\section{ABSTRACT}

Colletotrichum musae causes great damage in banana culture, and for this reason it is considered an important phytopathogenic agent. In this sense, the objective of this 
work was to evaluate the effects of temperature and plant extracts of Citrus aurantifolia Swingle, Citrus latifolia Tanaka and Allium sativum on the mycelial growth of $C$. musae. In the evaluation of the effect of the temperature were evaluated the temperatures $15,20,25,30$ and 35 and $40^{\circ} \mathrm{C}$ against the mycelial growth of $\mathrm{C}$. musae. The experimental design was completely randomized, using five replicates. Data were submitted to analysis of variance (ANOVA) and means were compared by the Tukey test (0.05). In the evaluation of antifungal activity, the concentrations of 0 , $50,100,150$ and $200 \mathrm{~L} / \mathrm{mL}$ of oil and of the individual extracts were added to the

BDA culture medium. The results of the different concentrations were submitted to analysis of variance, associated to the simple and multiple linear regression test, at the $1 \%$ level of significance. All analyzes were performed using the programming language $\mathrm{R}$. Temperatures of 25 and $30^{\circ} \mathrm{C}$ provided higher mycelial growth of the pathogen, with IVCM values of 1.7 and $1.3 \mathrm{~cm}$.day ${ }^{-1}$, respectively. In the test with the extracts of lemon taiti and garlic all concentrations tested showed inhibition of the pathogen. The lemon-galego extract presented the same results of the fungicide, inhibiting the total growth of the fungus. The plant extracts under study present potential for the alternative management of anthracnose.

KEYWORDS: Fungal control, Phytopathogen, Post-harvest diseases.

\section{INTRODUÇÃO}

A Banana é a segunda fruta de maior produção no Brasil, e corresponde a $16,5 \%$ do volume total de frutas produzidas no país, ficando atrás apenas da produção de laranja (SEAB, 2015). Seu cultivo é bastante difundido nacionalmente, com uma produção que superou os sete milhões de toneladas em 2017 (IBGE, 2017). No entanto, alguns entraves colaboram para redução da produtividade da bananicultura no Brasil, destacando-se problemas na sua cadeia produtiva, oriundos principalmente da perda pós-colheita causada por ataque de fungos (RANGEL et al., 2002).

O fungo Colletotrichum musae, causador da antracnose, doença de ocorrência predominante em pós-colheita, pode ser responsável por perdas de até $40 \%$ da produção de banana (PESSOA et al., 2007). Em termos econômicos seu ataque traz prejuízos, pois prejudica a comercialização do fruto (COUTO, 2004). Os sintomas da antracnose são caracterizados pela formação de manchas escuras e deprimidas e a progressão da doença é favorecida em ambientes de altas temperaturas e umidade, no qual, surgem frutificações rosadas do fungo e aumento no tamanho das lesões no fruto (KIMATI et al., 1997).

$\mathrm{O}$ uso de fungicidas sintéticos tem sido considerado como um dos métodos mais eficazes para controlar fitopatógenos (WIGHTWICK et al. 2010). No entanto, perdas na eficiência de fungicidas devido ao surgimento de patógenos resistentes têm promovido a busca por estratégias alternativas voltadas a maximizar a eficiência no controle de agentes fúngicos que causam doenças pós-colheita e riscos à segurança alimentar (WANG et al., 2018). A ação fungistática promovida por produtos vegetais é uma estratégia sustentável para o controle de doenças póscolheita (HAN et al., 2018; SHUPING; ELOFF, 2017; SHABANA et al., 2017). Trabalhos in vitro, mostraram o potencial de produtos vegetais frente a diversos patossistemas, devido sua capacidade fungitóxica direta, inibindo o crescimento micelial e a germinação de esporos de fungos (SCHWAN-ESTRADA et al., 2000; KOBAYASHI; AMARAL, 2018). 
Devido à crescente busca de medidas de controle de doenças de plantas com a finalidade de diminuir o uso de produtos sintéticos, este trabalho foi proposto com o objetivo de investigar os efeitos da temperatura e de extratos vegetais de Citrus aurantifolia Swingle (limão galego), Citrus latifolia Tanaka (limão taiti) e bulbos de Allium sativum (alho) sobre o crescimento micelial de C. musae, como medida alternativa ao uso de defensivos agrícolas no controle da antracnose.

\section{MATERIAL E MÉTODOS}

O trabalho foi conduzido nos Laboratório de Química e Solos e Fitopatologia da Universidade Federal do Acre, Campus Floresta Centro Multidisciplinar CMULTI, em Cruzeiro do Sul, Acre com coordenadas geográficas 7ํ 33" S., 72ํ4ㄹ" O e altitude média de $206 \mathrm{~m}$. O clima predominante da região, segundo a classificação de Köppen, é do tipo Af, caracterizado como tropical quente e úmido, com temperatura média anual de $24^{\circ} \mathrm{C}$ (ALVARES et al., 2014).

\section{Isolamento e cultivo do fungo}

O material infectado com sintomas de antracnose (Colletotrichum musae) foi coletado no mercado da cidade de Cruzeiro do Sul, Acre. Para isolar os fungos foram utilizados fragmentos dos materiais enfermos iniciando-se com o processo de desinfestação do material, submetendo-os em álcool $70 \%$ por 1 minuto, hipoclorito de sódio a $1 \%$ por 30 segundos e em água esterilizada. Após isso, o material foi transferido para placas de Petri de $9 \mathrm{~cm}$ de diâmetro, contendo em média $20 \mathrm{~mL}$ de meio de cultura BDA (batata dextrose e ágar). Após dez dias de incubação, as colônias foram purificadas e mantidas em câmara de germinação do tipo Biochemical Oxigen Demand (B.O.D.), a $25 \pm 2 \stackrel{\circ}{\circ}$, umidade de $70 \%$ e fotoperíodo de 12 horas para preservação do patógeno até o momento de realização dos experimentos conforme o método proposto por Ferreira et al. (2012).

\section{Efeito da temperatura sobre o crescimento micelial de $C$. musae}

Para o teste do efeito da temperatura, $20 \mathrm{~mL}$ de meio de cultura BDA ainda fundente foi vertido em placas de Petri de $9 \mathrm{~cm}$ previamente esterilizadas. Após 11 dias de crescimento das colônias purificadas, um disco de $8 \mathrm{~mm}$ de diâmetro, contendo o micélio de $C$. musae foi depositado no centro de cada placa. As placas contendo o material biológico foram seladas com papel aderente, identificadas e submetidas às temperaturas de $15,20,25,30,35$ e $40^{\circ} \mathrm{C}$, com fotoperíodo de 12 horas, durante sete dias em B.O.D., conforme o método de Grigoletti Júnior (1999). A avaliação do experimento iniciou às $24 \mathrm{~h}$ após sua instalação, realizando-se medições ortogonais do diâmetro das colônias diariamente, sendo que cada medição correspondeu à média de duas medidas diametralmente opostas da colônia fúngica, tendo como referência as placas testemunhas. Os dados obtidos nessa avaliação foram utilizados para calcular o Índice de Velocidade de Crescimento Micelial (IVCM), conforme a fórmula utilizada por Dias et al. (2005).

\section{Obtenção dos extratos de plantas}

Após a obtenção da casca de $C$. aurantifolia Swingle (limão galego) e $C$. latifolia Tanaka (limão taiti) e bulbos de Allium sativum (alho), foram pesados $10 \mathrm{~g}, \mathrm{e}$ posteriormente, triturados e homogeneizados suavemente em $100 \mathrm{~mL}$ de água destilada esterilizada, durante 10 minutos para obtenção dos extratos. Em seguida, 
o material foi filtrado e autoclavado. Os extratos aquosos foram utilizados imediatamente após sua obtenção.

\section{Efeito dos extratos vegetais sobre o crescimento micelial de $C$. musae}

Com base no melhor resultado do efeito de diferentes temperaturas sobre o crescimento micelial de $C$. musae foram testados os extratos de plantas de $C$. aurantifolia Swingle (limão galego), C. latifolia Tanaka (limão taiti) e $A$. sativum (alho). A atividade antifúngica das concentrações dos extratos de plantas foi avaliada através da inibição do crescimento micelial do patógeno submetido as concentrações de 0, 50, 100, 150 e $200 \mathrm{~L} / \mathrm{mL}$. A testemunha negativa consistiu do disco do fungo cultivado em meio BDA sem a presença dos extratos vegetais e como testemunha positiva foi utilizado fungicida Nativo nas mesmas concentrações dos extratos vegetais testados.

Desta forma, foi primeiramente adicionado o material vegetal ao meio BDA fundente com temperatura máxima de $45^{\circ} \mathrm{C}$, e em seguida foram vertidos em placas de Petri de $9 \mathrm{~cm}$ de diâmetro. Com o auxílio de um vazador de $0,5 \mathrm{~cm}$ de diâmetro foram retirados discos do meio de cultivo contendo isolados de $C$. musae, com aproximadamente 7 dias de incubação. As placas foram seladas com papel aderente e incubadas à temperatura de $25^{\circ} \mathrm{C}$, sob fotoperíodo de $12 \mathrm{~h}$. A avaliação do efeito das diferentes concentrações de extratos vegetais sobre o crescimento micelial foi realizada diariamente, medindo-se o diâmetro da área de crescimento micelial em dois eixos ortogonais (obtendo-se uma média das duas medidas diametricamente opostas). As avaliações foram encerradas no momento que a $1^{\underline{a}}$ placa cobriu totalmente a superfície do meio de cultura. Com a média dos resultados obtidos foi determinada a ação fungitóxica dos produtos vegetais, calculando-se a taxa de crescimento micelial sob os efeitos dos diferentes tratamentos em relação à testemunha. Neste trabalho, foi calculado o Percentual de Inibição do Crescimento (PIC) de acordo com a Equação 1.

$$
P I C=\frac{D T e-D T r}{D T e} * 100
$$

$$
\begin{aligned}
& \text { Em que: } \\
& P I C=\text { Porcentagem de Inibição de Crescimento } \\
& D T e=\text { diâmetro da testemunha } \\
& D T r=\text { diâmetro do tratamento }
\end{aligned}
$$

\section{Delineamento experimental e análises estatísticas}

O delineamento experimental utilizado para o teste da temperatura foi 0 inteiramente casualizado com cinco repetições para cada tratamento. Os resultados foram submetidos ao teste de normalidade (Shapiro Wilk) e homogeneidade de variâncias (Levene), e atendidas às premissas do teste paramétrico, foram submetidos à análise de variância (ANOVA) e as médias comparadas pelo teste Tukey $(p<0,05)$.

O ensaio da atividade antifúngica dos extratos vegetais obedeceu ao delineamento experimental inteiramente casualizado, empregando-se cinco repetições para cada tratamento (concentrações). Os resultados quantitativos foram submetidos à análise de variância, associada ao teste de regressão linear múltipla, verificando sempre o melhor ajuste, ao nível de $1 \%$ de significância. Os dados 
também foram submetidos à análise de Shapiro Wilk para investigar a normalidade dos resíduos e teste de Levene para aferir a homogeneidade de variâncias. As médias foram submetidas ao teste Tukey $(p<0,05)$. As análises foram realizadas utilizando a linguagem de programação $R$ ( $R$ Core Team, 2015).

\section{RESULTADOS E DISCUSSÃO}

\section{Efeito da temperatura sobre o crescimento micelial de C. musae}

As temperaturas de 25 e $30^{\circ} \mathrm{C}$ proporcionaram maior crescimento micelial do patógeno com valores de IVCM de 1,7 e 1,3 cm.dia ${ }^{-1}$, respectivamente (Figura 1). Já a temperatura de $15^{\circ} \mathrm{C}$ ocasionou considerável redução no crescimento micelial de Colletotrichum musae, e a temperatura de $40^{\circ} \mathrm{C}$ proporcionou completa inibição do crescimento micelial do patógeno (Figura 1).

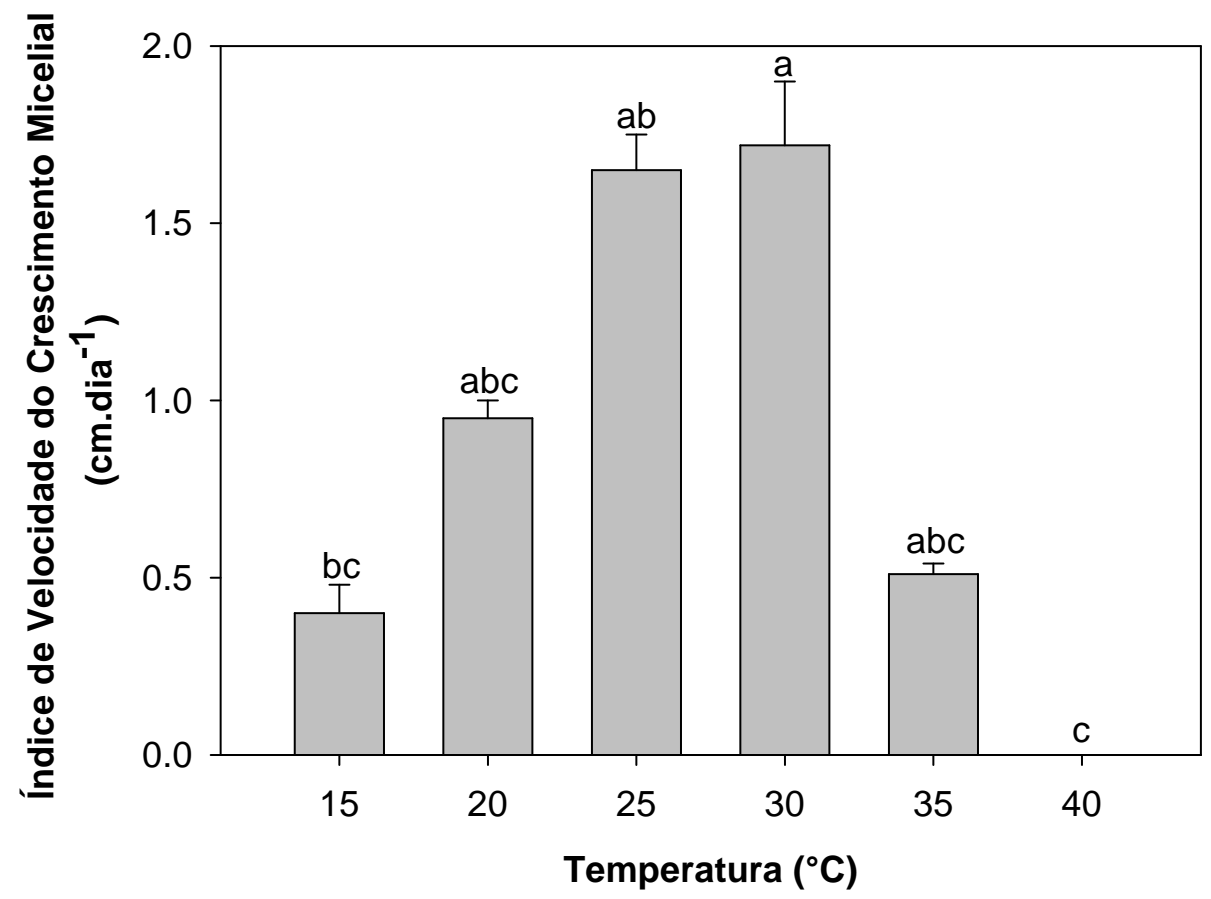

FIGURA 1. Efeito da temperatura no crescimento micelial de $C$. musae, agente causador da antracnose da banana (OLIVEIRA et al. 2018).

Em estudo avaliando o efeito da temperatura no crescimento micelial, produção e germinação de conídios de diferentes isolados de Colletotrichum sp., a temperatura que proporcionou o maior crescimento micelial dos diferentes isolados variou entre 22 e $28^{\circ} \mathrm{C}$ (DIAS et al., 2005). Resultados semelhantes foram obtidos por Poltronieri et al. (2013) que após avaliarem o efeito da temperatura no crescimento micelial de $C$. gloeosporioides constataram que o maior valor de IVCM foi obtido na temperatura de $28^{\circ} \mathrm{C}$, seguida pela a temperatura de $25^{\circ} \mathrm{C}$.

Vinnere et al. (2004) relataram que a temperatura ótima para o crescimento micelial de C. gloeosporioides encontra-se entre 26 e $28^{\circ} \mathrm{C}$. O efeito inibidor da temperatura sobre o crescimento dos fungos é bastante variável, e, no entanto, a maioria dos patógenos apresenta a faixa ideal para o crescimento entre 20 e $25^{\circ} \mathrm{C}$ (POLTRONIERI et al., 2013). O estudo sobre a biologia do patógeno é de grande 
importância para compreender a progressão da doença e, consequentemente, determinar medidas eficientes para o seu controle (MARCUZZO; LUIZ, 2017). E nesse sentido, o conhecimento da temperatura ideal é considerado de importância para o sucesso em programas de controle fitopatológico.

Efeito dos extratos vegetais no crescimento micelial de C. musae

Os resultados da análise de regressão revelaram interação significativa entre os fatores estudados (extratos vegetais $x$ concentrações), o que indicou diferença estatística na ação dos extratos vegetais sobre o crescimento micelial de $C$. musae nas diferentes concentrações quando comparadas a testemunha $(p<0,05)$. Em todos os tratamentos avaliados houve inibição do crescimento micelial (Figura 2). No entanto, nos tratamentos utilizando o extrato de limão galego e o fungicida Nativo foi verificado que houve completa inibição do patógeno desde a menor concentração $(50 \mathrm{~L} / \mathrm{mL}$ ). Com relação aos extratos de limão taiti e alho, houve relação entre o aumento da concentração dos extratos e a inibição do crescimento micelial do patógeno.

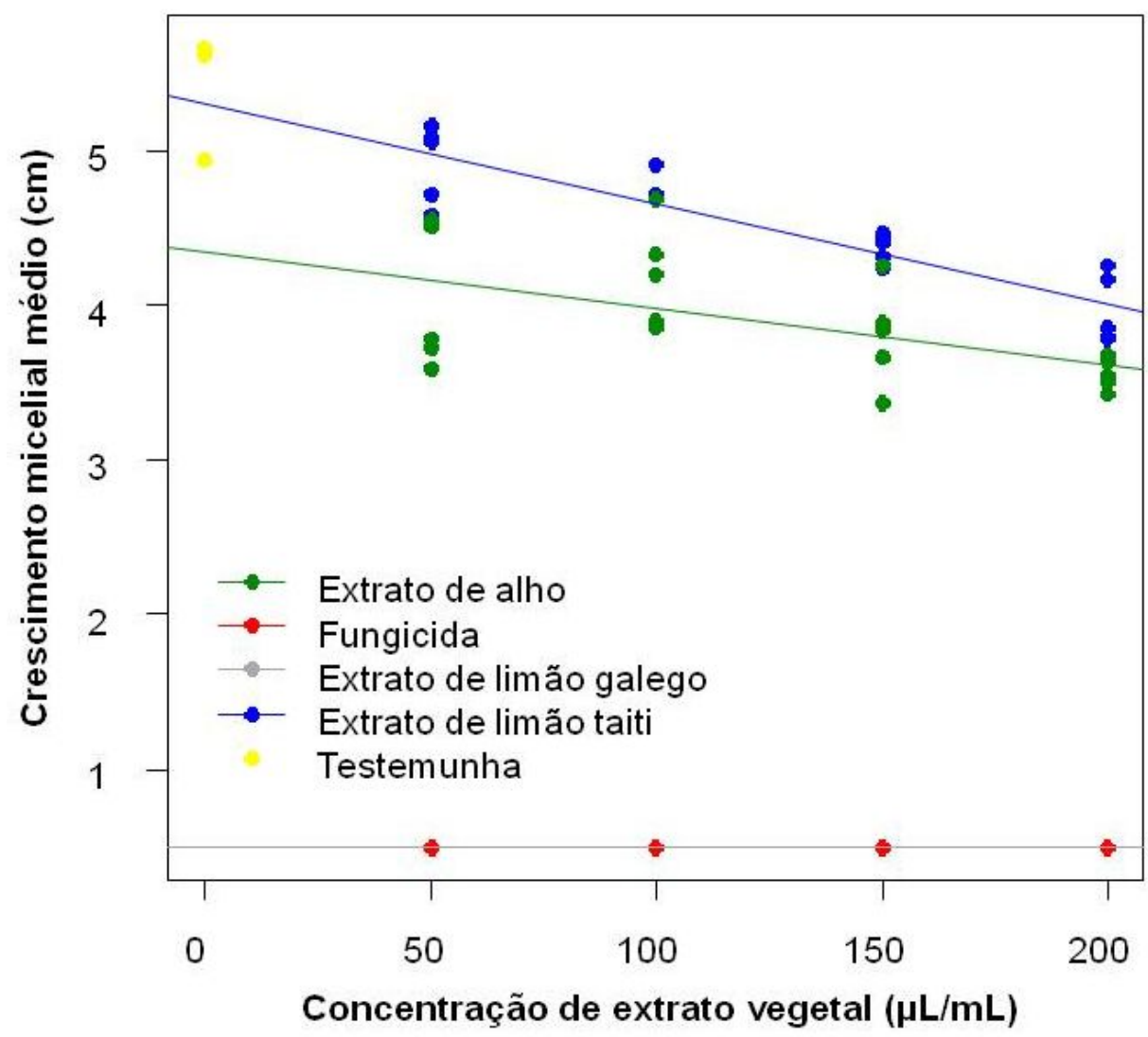

FIGURA 2. Efeito dos extratos vegetais sobre o crescimento micelial de $C$. musae (OLIVEIRA et al. 2018).

Marinho et al. (2018), analisando a atividade inibitória do extrato vegetal de Sapindus saponaria L. no controle do fungo Colletotrichum gloeosporioides, agente causador da antracnose em frutos de mamoeiro, constataram também que houve redução do crescimento micelial do fitopatógeno.

A utilização de extratos vegetais apresenta eficácia no controle de diversos gêneros de fungos. Gwa et al. (2018), em estudo com cinco espécies de plantas 
medicinais sobre o controle de Penicillium expansum, identificaram que Zingiber officinale Rosc., Piper nigrum Linn., Azadirachta indica A. Juss., Nicotiana tabacum Linn e Carica papaya Lam foram eficazes no manejo da podridão do inhame. $O$ resultado revelou que os extratos vegetais possuem compostos antimicrobianos capazes de inibir o crescimento mcelial de $P$. expansum.

A produção de moléculas bioativas pelas plantas é um mecanismo de defesa contra patógenos e pragas (OXENHAM, 2003). Nesse sentido, os efeitos antifúngicos e antimicrobianos são o resultado de moléculas isoladas ou a ação sinergética de substâncias produzidas pelas plantas (BAGAMBOULA et al. 2004).

Quanto ao percentual de inibição do crescimento micelial, o extrato de limão galego inibiu em $100 \%$ o crescimento micelial de C. musae, bem como o fungicida Nativo (Tabela 1). Já o extrato aquoso de alho, embora haja relatos na literatura sobre sua eficácia no controle de fitopatógenos, neste trabalho o melhor resultado foi $30 \%$ de inibição na concentração de $200 \mathrm{~L} / \mathrm{mL}$ (Tabela 1).

TABELA 1: Percentual de inibição do crescimento micelial de $C$. musae, causador da antracnose da banana.

\begin{tabular}{ccccc}
\hline \multicolumn{4}{c}{ Percentual de inibição dos extratos utilizados } \\
\hline $\begin{array}{c}\text { Concentrações } \\
(\text { L/mL) }\end{array}$ & Limão galego & Limão taiti & Alho & Fungicida \\
\hline 50 & 100 & 21 & 19 & 100 \\
100 & 100 & 24 & 16 & 100 \\
150 & 100 & 31 & 25 & 100 \\
200 & 100 & 38 & 30 & 100 \\
\hline
\end{tabular}

Nascimento et al. (2013) avaliaram o efeito de extratos de Ruta graveolens L., Mentha x villosa, Calendula officinalis L., Momordica charantia L., Symphytum officinale L., Ageratum conyzoides L. E Ricinus comunis L. sobre a inibição do crescimento micelial de Cercospora calendulae Sacc. in vitro, e também identificaram percentuais de inibição satisfatórios.

\section{CONCLUSÃO}

De acordo com os resultados obtidos, verificou-se que a temperatura de $25^{\circ} \mathrm{C}$ proporcionou maior crescimento micelial de $C$. musae e o menor crescimento foi verificado na temperatura de $15^{\circ} \mathrm{C}$, o que sugere a importância da temperatura no manejo e controle de doenças pós-colheita.

Além disso, observou-se que os extratos do limão taiti e alho inibiram o crescimento do fungo em todas as concentrações testadas.

O extrato do limão galego inibiu completamente o crescimento do fungo, proporcionando efeito similar ao do fungicida testado.

O controle da temperatura e a utilização de extratos vegetais são importantes ferramentas de controle de agentes fúngicos que causam perdas econômicas na produção de frutos de banana, e podem ser alternativas ao uso de defensivos agrícolas no controle da antracnose.

\section{AGRADECIMENTOS}

Agradecimentos à Universidade Federal do Acre - UFAC pelo apoio logístico e à Coordenação de Aperfeiçoamento de Pessoal de Nível Superior - CAPES pelo apoio e incentivo à pesquisa científica. 


\section{REFERÊNCIAS}

ALVARES, C. A; STAPE, J. L.; SENTELHAS, P. C.; GONÇALVES, J. L. M.; SPAROVEK, G. Köppen's climate classification map for Brazil. Meteorologische Zeitschrift. v. 22, n. 6, p. 711-728, 2014.

BAGAMBOULA, C. F.; UYTTENDAELE, M.; DEBEVERE, J. Inhibitory effect of thyme and basil essential oils, carvacrol, thymol, estragol, linalool and $p$-cymene towards Shigella sonnei and S. flexneri. Food Microbiology, v. 21, n. 1, p. 33-42, 2004. DOI: https://doi.org/10.1016/S0740-0020(03)00046-7

COUTO, E. F.; MENEZES, M. Caracterização fisiomorfológica de isolados de Colletotrichum musae. Fitopatologia Brasileira, v. 29, n. 4, p. 406-412, 2004. DOI: http://dx.doi.org/10.1590/S0100-41582004000400008

DIAS, M. B.; POZZA, E. A.; ABREU, M. S.; OROZCO MIRANDA, E. Efeito da temperatura no crescimento micelial, produção e germinação de conídios de Colletotrichum spp. isolados de Coffea arabica L. Ciência e Agrotecnologia, v. 29, n. 3, p. 545-552, 2005. DOI: http://dx.doi.org/10.1590/S1413-70542005000300006

FERREIRA, J. B.; NEVES, Y. Y. B.; NASCIMENTO, G. O.; FIGUEIREDO, A. L. V. F.; VENTURI, N. N. Óleos essenciais no controle de Colletotrichum gloeosporioides, Agente causal da antracnose em palmáceas. Enciclopédia Biosfera, v. 8, n. 14, p. 1-10, 2012.

GRIGOLETTI JÚNIOR, A.; LAU, D. Crescimento de isolados de Cylindrocladium spathulatum da Ervamate de cinco Regiões do Estado do Paraná. Boletim de Pesquisa Florestal, v. 38, p. 67-75, 1999.

GWA, V. I.; NWANKITI, A. O.; EKEFAN, E. J. Antifungal Effect of Five Aqueous Plant Extracts on Mycelial Growth of Penicillium Expansum Isolated from Rotted Yam Tubers in Storage). Acta Scientific Agriculture, v. 2, n. 6, p. 65-70, 2018.

HAN, J. W.; SHIM, S. H.; JANG, K. S.; CHOI, Y. H.; DANG, Q. L.; et al. In vivo assessment of plant extracts for control of plant diseases: A sesquiterpene ketolactone isolated from Curcuma zedoaria suppresses wheat leaf rust. Journal of Environmental Science and Health, v. 53, n. 1, p. 135-140, 2018. DOI: 10.1080/03601234.2017.1397448

IBGE. Instituto Brasileiro de Geografia e Estatística. Levantamento Sistemático da Produção Agrícola. Disponível em: <http://www.sidra.ibge.gov.br/bda/prevsaf/default.asp> Acesso em: 07 de Julho de 2018.

KIMATI, H.; AMORIM, L.; REZENDE, J. A. M.; BERGAMIN FILHO, A.; CAMARGO, L. E. A. Manual de fitopatologia: doenças das plantas cultivadas. 4. ed. São Paulo: Agronômica Ceres, v. 2, 1997.

KOBAYASHI, B. F., AMARAL, D. R. Efeito de extratos vegetais de plantas do Cerrado para controle de pinta-preta em tomateiro. Summa Phytopathologica, n. 44, v.2, 189-192, 2018. https://doi.org/10.1590/0100-5405/2194

MARCUZZO, L. L.; LUIZ, L. Influência da temperatura e do fotoperíodo na germinação in vitro de escleródios de Sclerotium cepivorum, agente causal da podridão branca do alho e da cebola. Summa Phytopathol, v. 43, n. 2, p. 1, 2017. DOI: https://doi.org/10.1590/0100-5405/178073 
MARINHO, G. J. P.; KLEIN, D. E.; LUIS, C.; JUNIOR, S. Evaluation of soapberry (Sapindus saponaria L.) leaf extract against papaya anthracnose. Summa phytopathol, v. 44, n. 2, p. 127-131, 2018. DOI: http://dx.doi.org/10.1590/01005405/175605

NASCIMENTO, J. M.; SERRA, A. P.; BACCHI, L. M.; GAVASSONI, W. L.; VIEIRA, M. C. Inibição do crescimento micelial de Cercospora calendulae Sacc. por extratos de plantas medicinais. Revista Brasileira de Plantas Medicinais, v. 15, n. 4, 2013. DOI: http://dx.doi.org/10.1590/S1516-05722013000500016

OXENHAM, S. K. Classification of an Ocimum basilicum germplasm collection and examination of the antifungal effects of the essential oil of basil. Ph.D. thesis, Glasgow, UK, University of Glasgow, 2003.

PESSOA, W. R. L. S.; OLIVEIRA, S. M. A.; DANTAS, S. A. F.; TAVARES, S. C. C. H.; SANTOS, A. M. G. Efeito da temperatura e período de molhamento sobre o desenvolvimento de lesões de Colletotrichum musae em banana. Summa $\begin{array}{llllll}\text { Phytopathologica, } & \text { v. } \quad 33, \quad n . \quad 2, & \text { p.147-151, } 2007 . & \text { DOI: }\end{array}$ http://dx.doi.org/10.1590/S0100-54052007000200008

POLTRONIERI, T. P. S.; AZEVEDO, L. A. S.; SILVA, D. E. M. Efeito da temperatura no crescimento micelial, produção e germinação de conídios de Colletotrichum gloeosporioides, isolados de frutos de palmeira juçara (Euterpe edulis Mart). Summa Phytopathol, v. 39, n. 4, p. 281-285, 2013.

R CORE TEAM. R: A Language and Environment for Statistical Computing. $R$ Foundation for Statistical Computing, Vienna, Austria, 2015.

RANGEL, A.; PENTEADO, L. A. C.; TONET, R. M. Cultura da banana. 2. ed. Campinas: CATI, 2002.

SCHWAN-ESTRADA, K. R. F., STANGARLIN, J. R., \& CRUZ, M. E. D. S. Uso de extratos vegetais no controle de fungos fitopatogênicos. Floresta, n. 30, v.2, 129137, 2000. https://doi.org/10.5380/rf.v30i12.2361.

SEAB - Secretaria de Estado da Agricultura e do Abastecimento - SEAB. Fruticultura: 2015.

SHABANA, Y. M.; ABDALLA, M. E.; SHAHIN, A. A.; EL-SAWY, M. M.; DRAZ, I. S.; et al. Efficacy of plant extracts in controlling wheat leaf rust disease caused by Puccinia triticina. Egyptian Journal of Basic and Applied Sciences, v. 4, n. 1, p. 67-73. 2017. DOI: https://doi.org/10.1016/j.ejbas.2016.09.002

SHUPING, D. S. S.; ELOFF, J. The use of plants to protect plants and food against fungal pathogens: a Review. African Journal of Traditional, Complementary and Alternative Medicines, v. 14, n. 4, p. 120-127, 2017.

VINNERE, O. Aproaches to species delineation in anamorphic (mitosporic) fungi: A study on two extreme cases. Comprehensive Summaries of Uppsala Dissertations from the Faculty of Science ad Technology, Uppsala, v.917, p.72, 2004.

WANG, Y.; FENG, K.; YANG, H.; ZHANG, Z.; YUAN, Y.; ET AL. Effect of cinnamaldehyde and citral combination on transcriptional profile, growth, oxidative damage and patulin biosynthesis of Penicillium expansum. Frontiers in Microbiology, v. 9, p. 1-14, 2018. DOI: 10.3389/fmicb.2018.00597 
WIGHTWICK, A.; WALTERS, R.; ALLINSON, G.; REICHMAN, S. M.; MENZIES, N. $W$. Environmental risks of fungicides used in horticultural production systems, 2010. Disponível em: http://cdn.intechopen.com/pdfs/12733/lnTechEnvironmental_risks_of_fungicides_used_in_horticultural_production_systems.pdf 